\title{
The perils of the imperfect expectation of the perfect baby.
}

\author{
Frank A Chervenak \\ Weill Medical College of Cornell University \\ Laurence B McCullough \\ Baylor College of Medicine \\ Robert L Brent \\ Thomas Jefferson University
}
Follow this and additional works at: https://jdc.jefferson.edu/pedsfp
Part of the Bioethics and Medical Ethics Commons, and the Pediatrics Commons Let us know how access to this document benefits you

\section{Recommended Citation}

Chervenak, Frank A; McCullough, Laurence B; and Brent, Robert L, "The perils of the imperfect expectation of the perfect baby." (2010). Department of Pediatrics Faculty Papers. Paper 33. https://jdc.jefferson.edu/pedsfp/33

This Article is brought to you for free and open access by the Jefferson Digital Commons. The Jefferson Digital Commons is a service of Thomas Jefferson University's Center for Teaching and Learning (CTL). The Commons is a showcase for Jefferson books and journals, peer-reviewed scholarly publications, unique historical collections from the University archives, and teaching tools. The Jefferson Digital Commons allows researchers and interested readers anywhere in the world to learn about and keep up to date with Jefferson scholarship. This article has been accepted for inclusion in Department of Pediatrics Faculty Papers by an authorized administrator of the Jefferson Digital Commons. For more information, please contact: JeffersonDigitalCommons@jefferson.edu. 


\title{
As submitted to \\ American Journal of Obstetrics \& Gynecology
}

And later published as:

The perils of the imperfect expectation of the perfect baby

\author{
Volume 203:101.e1 - 105.e1, August 2010
}

\section{DOI: 10.1016/j.ajog.2010.01.058}

\author{
Frank A. Chervenak, MD; Laurence B. McCullough, PhD; Robert L. Brent, MD, \\ PhD, DSc (Hon)
}

Advances in modern medicine invite the assumption that medicine can control human biology. There is a perilous logic that leads from expectations of medicine's control over reproductive biology to the expectation of having a perfect baby. This article proposes that obstetricians should take a preventive ethics approach to the care of pregnant women with expectations for a perfect baby. We use Nathaniel Hawthorne's classic short story, "The Birthmark," to illustrate the perils of the logic of control and perfection through science and then identify possible contemporary sources of the expectation of the perfect baby. We propose that the informed consent process should be used as a preventive ethics tool throughout the course of pregnancy to educate pregnant women about the inherent errors of human reproduction, the highly variable clinical outcomes of these errors, the limited capacity of medicine to detect these errors, and the even more limited capacity to correct them.

Key words: congenital malformation, informed consent, intrauterine growth restriction, perfect baby, prematurity, preventive ethics, reproductive risk, spontaneous abortions

Cite this article as: Chervenak FA, McCullough LB, Brent RL. The perils of the imperfect expectation of the perfect baby. Am J Obstet Gynecol 2010;203:101.e1-5.

Patients often come to their physicians with requests for diagnostic tests and treatments, sometimes invasive tests and treatments. This is especially the case in obstetric practice. The prevalence with which pregnant women make requests of their obstetricians varies in different populations of pregnant women. However, obstetricians are familiar with-and are often troubled by- requests for diagnostic tests and for specific interventions, such as the detailed birth plans that some pregnant women present. These requests for clinical management obviously reflect the values and priorities of pregnant patients and therefore should be taken seriously. 
Sometimes, however, such requests reflect something more: the quest for control over human biology and the pursuit of perfection that such control should attain. The expectation of a perfect baby follows logically from the expectation that medicine can control human biology. This logic of expectations of control and perfection can become perilous. Sometimes this logic is expressed in requests that cause obstetricians to become uncomfortable, eg, when a birth plan is internally inconsistent or sets conditions such as no analgesia or no cesarean delivery that, later, may not be consistent with evidence based clinical reasoning and therefore professional integrity. The logic of expectations of control and perfection can also lead to rejection of resuscitation in the delivery room or of subsequent neonatal critical care, even when these are reliably expected to be life saving and achieve a good functional outcome.

In short, the logic of expectations of control and even perfection of pregnant women who embrace this logic is fraught with the potential for ethical conflict. The purpose of this article is to identify some of the sources for this ethical conflict and propose a preventive ethics approach to replacing the logic of the expectations of control and perfection with more realistic and therefore more appropriate expectations.

\section{The perils of the logic of expectations of control and perfection: a cautionary tale}

We start with one of the most compelling accounts of the perils of the logic of expectations of control and perfection in medicine, Nathaniel Hawthorne's ${ }^{1}$ (1804-1864) "The Birthmark." Brilliantly anticipating the problems we address, Hawthorne relates the story of a woman renowned for her beauty, named Georgiana. Her beauty, however, appears incomplete: she has a birthmark in the shape of a hand on her cheek. Aylmer, her husband, comes to dislike his wife's birthmark. Georgiana, perhaps as a result of Aylmer's influence, comes to dislike her birthmark as well. Alymer plans to use his scientific skills to eradicate the birthmark and make his wife's beauty complete, perfect. His thinking epitomizes the logic that leads inexorably from an exaggerated expectation of scientific control over human biology to its perfection.

Driven by this logic, Aylmer prepares a special liquid, a "chemical experiment," to rid her of the birthmark. He assures her: "The concoction of the draft has been perfect. ... Unless all my science have failed me, it cannot fail." Despite concern for danger, Georgiana duly consumes the "powerful cosmetic." She falls into a sleep and her

birthmark begins to disappear. Her first words on awakening are "My poor Aylmer." "'Poor? Nay, richest, happiest, most favored!' exclaimed he. 'My peerless bride, it is successful! You are perfect!"” She is also dying and expires as her birthmark fades altogether from her cheek. The expectation of control over human biology and the pursuit of perfection encouraged by such an expectation have exacted a terrible price.

\section{The perils of the logic of expectations of control and perfection in pregnancy}

A directly parallel logic of expectation of control and pursuit of perfection in pregnancy today can also exact a price, though, of course, not so terrible. This article will take a preventive ethics approach to the imperfect concept of a perfect baby. Preventive ethics has 2 components: (1) identifying the conditions in clinical practice that can lead to ethical conflict; and (2) using the informed consent process to address and defuse conditions that create the potential for conflict. ${ }^{2}$ The conditions in clinical practice that promote the concept of the perfect baby and can lead to ethical conflict in the care of pregnant patients are exaggerated expectations about the ability to control human reproductive biology. We will first identify these conditions and then describe an 
informed consent process designed to defuse the logic of expectations of control and perfection.

Modern fetal diagnosis and therapy feed public expectations of medicine's ability to control human reproductive biology. In a single generation, technological and interpretive advances have transformed fetal imaging. In the developed world we have long ago left the world of grainy, bistable, static images that few physicians were competent to interpret. We now have 4-dimensional, real-time ultrasound images that can be easily appreciated by the lay public who have never before seen an ultrasound image of a developing fetus. Physicians, long accustomed to imaging technology, look on the results with a diagnostic eye, what Foucault ${ }^{3}$ called the "clinical gaze." The clinical gaze appropriately medicalizes what it sees, because physicians are expected to diagnose and manage fetal abnormalities. One result is that the fetus may become a patient who can be diagnosed and treated, analogous to a newborn infant. ${ }^{4}$

The lay or social gaze is not the same, because, as a rule, it is scientifically and clinically untrained. Laypersons see pictures of babies, not images of anatomy and physiology. Pregnant women and those involved in their pregnancies with them see an immediate and visually arresting picture of the fetus, sometimes with a coppery shimmer. Magnetic resonance pictures can be even more visually arresting, especially of the fetal head and facial features. The experience of "seeing" the fetus can be a moving and bonding experience for the pregnant woman and her partner.

Given the intensity and power of fetal pictures, it is not unreasonable for laypersons to assume that the well-trained physician can see everything and therefore control human biology and thereby assure perfection. This linking of an expectation of control with the pursuit of perfection can feed the expectation that medicine can predict human reproductive biology with little or no risk. After all, fetal images can be made routinely, simultaneously, and without risk. It is a small next step to the expectation that medicine can predict the perfect baby.

Invasive fetal diagnosis from chorion villus sampling or amniocentesis results in karyotyping that is virtually certain in its ability to diagnose obvious aneuploidy. Karyotyping can encourage binomial thinking among some physicians that either there is a chromosomal abnormality or not, with the absence of abnormality resulting in reassurance. ${ }^{5}$ The lay translation can be quite different: either something is wrong or everything is fine. What the physician thinks is simply reassurance can nonetheless encourage the expectation of perfection for the patient.

It is common knowledge that cesarean delivery can be life saving for the fetus, eg, from complete placenta previa or prolonged bradycardia. It is also common knowledge that cesarean delivery can reduce morbidity, eg, from breech presentation. The introduction of steroid therapy to enhance fetal lung maturity has been shown to improve outcomes for infants born prematurely. Quality prenatal care that is initiated early in the pregnancy does not guarantee the prevention of prematurity. The administration of folic acid at $400 \_\mathrm{g} / \mathrm{d}$ throughout pregnancy can markedly reduce the incidence of neural defects, however it does not prevent all neural tube defects. ${ }^{6,7}$ The introduction of RhoGAM (Ortho-Clinical Diagnostics, Raritan, NJ) has markedly reduced the incidence 
of erythroblastosis fetalis. Intrauterine blood transfusion, though rarely needed for this condition, is the most well-established form of invasive fetal therapy and can be life saving for the fetus. More invasive forms of experimental fetal therapy, while performed only in a few centers, have been introduced. The publicity that can surround such surgery can give it an impact on public expectations that can be considerable, eg, in the common use of "miracle" to describe such innovative fetal therapy. ${ }^{8}$ Hospitals are not above encouraging such publicity, to market themselves in wider national and international markets. The drama of the publicity about such fetal therapy in the public arena obscures the rarity of its occurrence and clinical utility. The impression that fetal therapy is an expanding option encourages the belief in the ever-expanding power of medicine to control human reproductive biology.

The consumer rights movement has appropriately encouraged patients, especially pregnant patients, to speak up for themselves. The discourse of patients' rights can be misused, especially when it encourages patients to make excessive demands on physicians, eg, presenting detailed birth plans and requesting cesarean delivery in the absence of either fetal or maternal indications. ${ }^{9}$ Sometimes implicit in these expressions of patients' rights is the belief that laypersons can set the standard of care for clinical practice. The failure of physicians to adhere consistently to the discipline of evidencebased reasoning in obstetric practice has, ironically, supported this belief. It is a small step from the belief that laypersons can set the standard of care to the belief that patients can control human reproductive biology by making the right demands on their obstetricians.

Scientifically disciplined clinical judgment does not support the generalization from occasional success in clinical practice to uniform success. Lay thinking that is not scientifically disciplined can support this mistaken generalization. If patients have the belief that physicians can control human reproductive biology, bad outcomes must be the result of defective clinical judgment and practice, ie, malpractice.

The safe, effective termination of pregnancy before viability can encourage the belief that a pregnant woman can control all the outcomes of pregnancy. This belief may mean that the errors of human reproduction can be detected through fetal diagnosis and eliminated through termination of pregnancy. The biological reality is that not all lessthan-perfect outcomes can be detected prenatally.

\section{Fashioning the informed consent process to prevent exaggerated expectations about the ability to control human reproductive biology}

The informed consent process should be used by obstetricians early in prenatal care, or ideally, preconception, as a preventive ethics tool to defuse exaggerated expectations about the ability to control human biology. ${ }^{2}$ The first step in this informed consent is to provide patients with a succinct education about the imperfections of human reproduction and the limits of medicine to alter these imperfections (Table 1). ${ }^{10,11}$

No pregnant woman should begin her pregnancy with the idea that anyone can guarantee the birth of a normal baby. While there are some preventive measures (Table 2), such as vaccination against German measles (rubella vaccine), taking adequate 
amounts of folic acid (400 $\mu \mathrm{g} / \mathrm{d}$ as a minimum), ${ }^{12}$ some birth defects cannot be prevented. The concept to communicate is that the ability of medicine or patient's behaviors to improve outcomes is limited. Therefore, we cannot guarantee that every birth will be normal. This information should be communicated as part of routine prenatal care. ${ }^{2}$

All physicians who care for pregnant women should be aware of the pertinent scientific information on background reproductive risks (Table 1) ${ }^{10,11}$ and the etiology of congenital malformations (Table 3). ${ }^{10,11}$ In addition, while there are high-risk conditions such as multiple gestation, prematurity with its complications such as cerebral palsy and bronchopulmonary dysplasia can occur in any pregnancy as well as in full-term newborns (Table 1). The physician should strive for a term pregnancy, although doing so is no guarantee that the risks usually associated with prematurity cannot occur in full-term newborns.

Patients do not need to be provided this information in detail but do need to be informed about the risks of birth defects, miscarriage, and prematurity. Every pregnant woman should be told the following information (adjusted for the patient's educational level): "If you are healthy and have no personal or family history of reproductive or developmental defects, you began your pregnancy with a 3\% risk of birth defects. Once you knew you were pregnant, having missed your first menstrual period, you had a $15 \%$ risk of miscarriage. There is also a risk of prematurity and complications. These risks apply to all pregnant women." Physicians should be clear with patients that many congenital malformations (Table 3) have an unknown etiology so that, if a birth defect occurs, blame will not be inappropriately attributed to patients' behaviors, exogenous exposures, or obstetric management. ${ }^{13,14}$

Ultrasound technology and genetic diagnosis can identify many anomalies. However, pregnant women need to know that, although we have made great advances in the past 50 years, we are not close to being able to diagnosis or predict every genetic disease, anatomical malformation, or biochemical defect in each pregnancy and thus guarantee a normal pregnancy.

Obstetricians need to be aware of the reasons why we cannot diagnose all developmental problems. Some genetic diseases and hereditary anatomical malformations are due to mutations that occur during oogenesis or spermatogenesis (the development of the sperm or the ovum) (Table 1). Therefore, there is no family history of these diseases. Chromosomal microarray analysis has the potential to identify thousands of genetic diseases and disorders, outstripping the current diagnostic capacity of karyotyping by amniocentesis or chronic villus sampling. ${ }^{15}$ However, even when genetic abnormalities or hereditary anatomical defects are discovered by diagnostic tests, there may be no information about the clinical significance of such findings. Many anatomical malformations may not be recognizable in utero and will not be able to be diagnosed for months, or even years, after the child is delivered. Autism, polycystic kidney disease, mental retardation, learning disability, schizophrenia, and many other serious behavior disorders are in this category. While many congenital malformations can be diagnosed in utero, attempts to treat the fetus surgically or medically are often experimental, are not curative, and continue to have significant risks of mortality and morbidity. 
Even if experimental fetal therapy is available, it is uncertain if it should be utilized. Once a developmental diagnosis had been confirmed, it is not an easy task to determine what can be done (pregnancy interruption, in utero therapy, or expectant management). Physicians should be aware that many couples are willing to embark on experimental intervention in the mistaken assumption that, in their case, it will work. Physicians should be prepared to disabuse pregnant women who believe that the intervention will work and therefore do not appreciate its experimental nature, a confusion misconception." Finally, it is important to emphasize that many pregnant patients are optimistic about the advances in medicine and are confident that their physicians will solve all problems that could occur with their pregnancy. However, this version of the expectation of a perfect baby assumes powers of medicine to control human reproduction that medicine does not possess. There will almost certainly continue to be a significant percentage of anatomical birth defects that result from unpreventable developmental errors.

\section{Conclusion}

The obstetrician whose patient expresses the hope for a perfect baby should give this matter the serious and sensitive attention it deserves: a preventive ethics approach designed to educate the pregnant woman about the inherent errors of human reproduction, the highly variable clinical outcomes of these errors, the limited capacity of medicine to detect these errors, and the even more limited capacity to correct them. The message to convey is that perfection in pregnancy is not attainable now or even in the foreseeable future. Some pregnant women may be influenced by the expectation of perfection and therefore may believe that anything less is a disaster. Appropriate counseling can help them to realize that the fetus' condition and prospects are better than they think.

Physicians should keep in mind and help patients appreciate the ancient wisdom of the Hippocratic text, The Art, ${ }^{16}$ which emphasizes that the power of the art and science of medicine to alter the course of disease and injury is always limited. When physicians ignore these limits, they experience a kind of "madness" from which Aylmer suffered, ie, expecting more from medicine than its limited diagnostic and therapeutic capacities justify. In "The Birthmark," we can now see that Aylmer failed to meet the standards of preventive ethics and evidence-based reasoning when he said, "The concoction of the draft has been perfect. . . . Unless all my science have failed me, it cannot fail."1 Aylmer is thus an exemplar of what physicians should not do in response to the quest for the perfect baby.

In more contemporary terms, clinical judgment should be disciplined by scientific information of the kind we have presented. The preventive ethics response in the search for the perfect baby should use the informed consent process to discipline the expectations of pregnant women to the greatest extent possible. We believe that this preventive ethics approach should be taken with every pregnant woman, to prepare her for the inherent uncertainties of pregnancy and its clinical management. Physicians should assume that, with adequate counseling and support, pregnant women are indeed capable of making scientifically disciplined decisions, if informed consent is 
appropriately evidence based, as has been shown for decision making about invasive prenatal diagnosis after first-trimester risk assessment. ${ }^{17}$

\section{REFERENCES}

1. Hawthorne N. The birthmark. In: Pearson NH, ed. The complete novels and selected tales of Nathaniel Hawthorne. New York: Random House, 1937:1021-33.

2. Chervenak FA, McCullough LB. Clinical guides to preventing ethical conflicts between pregnant women and their physicians. Am J Obstet Gynecol 1990;162:303-37.

3. Foucault M. Naissance de la Clinique: Une Archéologie du régard médical [The birth of the clinic: an archeology of medical perception]. Sheridan Smith AM, trans. New York: Pantheon;1973.

4. McCullough LB, Chervenak FA. Ethics in obstetrics and gynecology. New York: Oxford University Press; 1994.

5. Brent RL. Saving lives and changing family histories: appropriate counseling of pregnant women and men and women of reproductive age, concerning the risk of radiation exposures during and before pregnancy. Am J Obstet Gynecol 2009;200:4-24.

6. Brent RL, Oakley GP. Triumph or tragedy: the present FDA program of enriching grains with folic acid. Pediatrics 2006;117:930-2.

7. Bell KN, Oakley GP Jr. Update on prevention of folic acid-preventable spina bifida and anencephaly. Birth Defects Res (Part A) 2009;85: 102-7.

8. Jones M. A miracle, and yet. New York Times Magazine. July 15, 2001:38-43.

Available at: http://www.nytimes.com/2001/07/15/magazine/ a-miracle-and-

yet.html?scp_1\&sq_A\%20Miracle,

\%20and\%20Yet\&st_cse. Accessed Nov. 13, 2009.

9. Kalish RB, McCullough LB, Chervenak FA. Decision-making about cesarean delivery. Lancet 2006;367:883-5.

10. Brent RL. Utilization of developmental basic science principles in the evaluation of reproductive risks from pre- and postconception environmental radiation exposures. Paper presented at the 33rd Annual Meeting of the National Council on Radiation Protection and Measurements. The effects of pre- and postconception exposure to radiation; April 2-3, 1997; Arlington, VA. Teratology 1999;

59:182-204.

11. Brent RL. Environmental causes of human congenital malformations: the pediatrician's role in dealing with these complex clinical problems caused by a multiplicity of environmental and genetic factors. In: Brent RL, Weitzman M, eds. Pediatric supplement: vulnerability, sensitivity and resiliency of infants, children and adolescents to environmental agents. Pediatrics 2004;113(4Suppl):957-68.

12. Brent RL, Oakley GP Jr. Commentary: the FDA must require the addition of more folic acid in "enriched" flour and other grains. Pediatrics 2005;116:753-5.

13. Brent RL. How does the physician avoid prescribing drugs and medical procedures that have reproductive and developmental risks? Medical legal issues in perinatal medicine. Clin Perinatol 2007;34:233-62.

14. Brent RL. Litigation-produced pain, disease and suffering: an experience with congenital malformation lawsuits. Teratology 1977;16:1-14. 
15. Papp $Z$ and International Academy of Perinatal Medicine. Ethical challenges of genomics for perinatal medicine: the Budapest declaration. Am J Obstet Gynecol 2009;201:336.

16. Hippocrates. The art. In: Jones WHS, trans. Hippocrates. Vol I. Cambridge, MA: Harvard

University Press, 1923.

17. Nicolaides KH, Chervenak FA, McCullough LB, Avgidou K, Papageorghiou A. Evidencebased obstetric ethics and informed decisionmaking by pregnant women about invasive diagnosis after first-trimester risk assessment of risk of trisomy 21. Am J Obstet Gynecol 2005;193:322-6.

18. MacDonman MF, Mathews TJ. Behind international rankings of infant mortality: how the United States compares with Europe. NCHS Data Brief \#23, Nov. 2009. Washington DC: U.S. Department of Health and Human Services Centers for Disease Control and Prevention; 2009:4. 